\title{
EXPORTAÇÕES BRASILEIRAS DE CASTANHA-DO-PARÁ (Bertholletia excelsa, H.B.K), SOB A ÓTICA DE CONCENTRAÇÃO DE MERCADO
}

\author{
BRAZILIAN EXPORTS OF CASTANHA-DO-PARÁ (Bertholletia excelsa, H.B.K), UNDER THE \\ OPTICS OF MARKET CONCENTRATION
}

\author{
Gustavo Silva Oliveira ${ }^{1}$, Maycon Thuan Saturnino da Silva², Taíze Caroline Dreyer ${ }^{3}$, \\ Gabriel de Mello Freire, Gabriel Agostini Orso ${ }^{5}$, Jaqueline de Paula Heimann ${ }^{6}$ \\ 1, 2, 4, 5,6 Universidade Federal do Paraná, Curitiba, Paraná, Brasil-gustavo_ccp@hotmail.com, \\ mayconthuan@hotmail.com,gabrieldmellof@hotmail.com,gabrielorso16@gmail.com \& \\ jaquelineheimann@yahoo.com.br
}

${ }^{3}$ Universidade do Estado de Santa Catarina, Lages, Santa Catarina, Brasil - taize_dreyer@hotmail.com

\section{RESUMO}

As atividades florestais se intensificaram em virtude do mercado globalizado e apresentam grande potencial frente ao crescente comércio de produtos florestais entre distintos países. Assim, a Castanha-do-Pará (Bertholletia excelsa, H.B.K) apresenta grande importância econômica, tornando o Brasil o maior produtor e exportador dos múltiplos produtos desta espécie. Considerando a importância de pesquisas referentes a concentração de mercado das exportações como instrumento para a tomada de decisão, este trabalho teve como objetivo analisar as medidas de concentração e desigualdade das exportações brasileiras de Castanha-do-Pará, no período de 2007 a 2017. Para isto, utilizou-se os índices de concentração Hirshman-Herfindahl (IHH) e a razão de concentração (CR4 e CR8) e para desigualdade o coeficiente de Gini (G). Os dados utilizados nas análises foram obtidos do portal de informação da Organização das Nações Unidas - UNCONTRADE. A evolução das exportações registrou retração gradativa a partir de 2015. O índice (IHH) apresentou valores de alta concentração e o CR4 e CR8 um grau de concentração muito alto. Já o índice (G) indicou desigualdade de média a forte. Assim, recomenda-se a análise dos índices em conjunto, com o intuito de evitar conclusões precipitadas e o desenvolvimento de estratégias visando atrair outros países no processo de exportação.

PALAVRAS-CHAVE: Economia florestal, Market share, Mercado internacional.

\section{ABSTRACT}

Forestry activities have intensified due to the globalized market and have great potential in the face of growing trade in forest products between different countries. Thus, Brazil nut (Bertholletia excelsa, H.B.K) has great economic importance, making Brazil the largest producer and exporter of the many products of this species. Considering the importance of researches related to the concentration of the export market as a tool for decision making, this work had the objective of analyzing the measures of concentration and inequality of the Brazilian exports of Castanha-do-Pará, from 2007 to 2017. For Hirshman-Herfindahl concentration index (HHI) and concentration ratio (CR4 and CR8) were used and the Gini coefficient (G) was used for inequality. The data used in the analyzes were obtained from the information portal of the United Nations - UNCONTRADE. The evolution of exports registered gradual retraction from 2015. The index (HHI) presented values of high concentration and CR4 and CR8 a very high concentration degree. The index $(G)$ indicated mean to strong inequality. Thus, it is recommended to analyze the indices together, in order to avoid hasty conclusions and the development of strategies aimed at attracting other countries in the export process.

KEYWORDS: Forest economics, Market share, International market. 


\section{INTRODUÇÃO}

No contexto atual, verifica-se que as atividades florestais se intensificaram em virtude do mercado globalizado e que apresentam grande potencial frente ao crescente comércio de produtos florestais entre distintos países e pelo interesse de diversas empresas pelas florestas.

Neste sentido, a castanheira, conhecida popularmente como Castanha-do-Pará e/ou Castanha-do-Brasil, pertencente à família Anacardiáceas, cujo nome cientifico é (Bertholletia excelsa, H.B.K) contém grande importância econômica, tendo seus frutos alto teor calorífico e proteico, além das questões de combate a radicais livres e usos farmacológicos (LARSON \& SILVA, 1976; MACEDO \& SOARES, 2015). Além do principal produto, amêndoa, esta espécie apresenta subprodutos que também podem ser explorados comercialmente, como óleos, farelo ou torta, leite de Castanha e ouriço, além da boa qualidade da madeira de reflorestamentos e fonte de sementes comestíveis apreciadas em várias partes do mundo. (COLLARES, 2006). Ademais, esta espécie é altamente diversificada e ecologicamente dominante em muitas florestas da região norte do Brasil, sendo considerada um símbolo do Rio Negro.

Em relação ao mercado e comercialização dos múltiplos produtos da espécie, o Brasil destaca-se como o maior produtor e exportador. De acordo com Cardarelli \& Oliveira (2000) cerca de $90 \%$ da produção nacional é exportada. No ano de 2015 o Brasil exportou o equivalente a US\$ 41,56 milhões em Castanha-do-Pará. Entretanto, no ano de 2017, a receita com a exportação foi de apenas US\$11,96 milhões, o valor mais baixo desde 2009 (FORMIGONI, 2018).

Neste contexto, em virtude da importância econômica do segmento no Brasil, considerando mercados poucos explorados e com grande potencial de desenvolvimento verifica-se a relevância de estudos sobre a estrutura dos principais mercados importadores do produto, corroborando com a tomada de decisões voltadas a decisões estratégicas (FEIJÓ et al., 2003). Dentre os estudos que abordam a concentração e desigualdade das exportações brasileiras de produtos florestais, destacamse: Gama \& Sousa (2010), Soares et al. (2014), Heimann et al. (2015) e Oliveira et al. (2017).

Reconhecida a importância de pesquisas referentes a concentração de mercado das exportações como instrumento para a tomada de decisão, este trabalho teve como objetivo analisar as medidas de concentração e desigualdade das exportações brasileiras de Castanha-do-
Pará, no período de 2007 a 2017.

\section{MATERIAL E MÉTODOS}

\section{Fonte dos dados}

Os dados utilizados na mensuração da concentração e desigualdade do mercado dos principais importadores brasileiros de Castanha-do-Pará, para o período de 2007 a 2017, foram obtidas no portal de informação da Organização das Nações Unidas UNCOMTRADE - United Nations Commodity Trade, considerando-se o capítulo 0801.21 - Castanha-do- Pará (Castanha do Brasil) com casca (UNCOMTRADE, 2019).

Posteriormente, coletou-se séries anuais do valor das exportações brasileiras em Dólar (US\$) e deflacionou-se pelo CPI (Consumer Price Index) norte-americano, tomando-se como ano base o de 2007, por representar o primeiro ano da série.

\section{Procedimentos metodológicos}

Índice de Hirshman-Herfindahl

O Índice Hirshman-Herfindahl $(I H H)$ caracteriza-se como um método de análise de concentração de mercado, apresentando benefícios como a capacidade de agregar o total de países dentre os quais as exportações são destinadas (RESENDE, 1994).

Neste estudo, calculou-se o índice com base na participação de cada país de destino das exportações brasileiras. Em conformidade ao estudo de Coelho Júnior et al. (2013) o IHH é calculado por meio da Equação 1.

$$
I H H=\sum_{i=1}^{n} S i^{2}
$$

Em que: $n=$ número de países para os quais o Brasil exporta; e $\mathrm{Si}=$ market share do país $i$ para o valor das exportações.

Sendo assim, o $\mathrm{IHH}$ evidencia os pesos relativos da participação de cada país. Elevando-se ao quadrado o market share dos países, atribuiu-se um maior peso aos que possuem maior participação. Resende (1994) descreve que a utilização dessa equação implica em um intervalo de variação entre 0 e 1 para o $\mathrm{IHH}$. Assim, Índice $I H H<0,1$ indica um mercado altamente competitivo; < 0,15 indica um mercado não concentrado; $0,15 \leq I H H \leq$ 0,25 indica concentração moderada e $>0,25$ indica alta concentração. 
Razão de concentração

A razão de concentração caracteriza-se pela indicação da estrutura de mercado especifico (SCHMIDT \& LIMA, 2002). Sendo assim, considera-se a atuação no mercado internacional dos $k$ (sendo $k=1,2, \ldots, n$ ) maiores países exportadores. A Equação 2, para o cálculo da razão de concentração é dada conforme Bain (1959).

$$
C R(k)=\sum_{i=1}^{k} S i
$$

Em que: $C R(k)=$ razão de Concentração de $\mathrm{k}$ países exportadores; e $\mathrm{Si}=$ market-share, em porcentagem, do país i para o valor das exportações.

Posteriormente, utiliza-se o $C R(4)$ e o $C R$ (8) para a análise de concentração dos países. Conforme o valor do índice aumenta, eleva-se o poder dos maiores países exportadores. A Tabela 1, ilustra os diferentes níveis de concentração e as respectivas classificações para $C R(4)$ e $C R(8)$.

Tabela 1. Classificação do grau de concentração dos maiores países exportadores.

\begin{tabular}{ccc}
\hline Grau de concentração & $\boldsymbol{C R}$ (4) (\%) & $\boldsymbol{C R}$ (8) (\%) \\
\hline Muito Alto & 75 ou mais & 90 ou mais \\
\hline Alto & $65-75$ & $85-90$ \\
Moderadamente Alto & $50-65$ & $70-85$ \\
\hline Moderadamente Baixo & $35-50$ & $45-70$ \\
Baixo & 35 ou menos & 45 ou menos \\
\hline
\end{tabular}

Fonte: Bain (1959).

Coeficiente de Gini (G)

O coeficiente de Gini (G), é utilizado para medir o grau de desigualdade das exportações dos países, uma vez que uma concentração elevada implica em uma desigualdade maior. O cálculo do índice segue a Equação 3.

$$
\mathrm{G}=1-\sum_{\mathrm{i}=1}^{\mathrm{n}} \frac{\mathrm{C}_{\mathrm{ij}}+\mathrm{C}_{\mathrm{j}}}{\mathrm{n}}
$$

Em que: $n$ = número de países exportadores; $C i j=$ participação cumulativa das exportações mundiais em ordem crescente; $\mathrm{Cj}=$ market share, em porcentagem, do país i para o valor das exportações mundiais.

O índice assume valores entre "zero" (ausência de concentração/igualdade absoluta entre todos os componentes do universo examinado) e "1" (concentração absoluta/desigualdade total). Deste modo, para classificação medida por este índice, utilizou-se a escala conforme Tabela 2.

Tabela 2. Classificação do Índice de Gini

\begin{tabular}{lc}
\hline Índice de Gini & Classificação \\
\hline $0,101-0,250$ & Desigualdade nula a fraca \\
$0,251-0,500$ & Desigualdade fraca a média \\
$0,501-0,700$ & Desigualdade média a forte \\
$0,701-0,900$ & Desigualdade forte a muito forte \\
$0,901-1,000$ & Desigualdade muito forte a absoluta \\
\hline
\end{tabular}

Fonte: Câmara (1949) apud Silva et al. (1992).

\section{RESULTADOS E DISCUSSÃO}

Analisando a evolução das exportações brasileiras de Castanha-do-pará em relação à quantidade e valor (Figura 1) observa-se que estas apresentaram tendência de decréscimo a partir de 2008, tendo o valor atingido seu pico em 2012 e a quantidade em 2015.

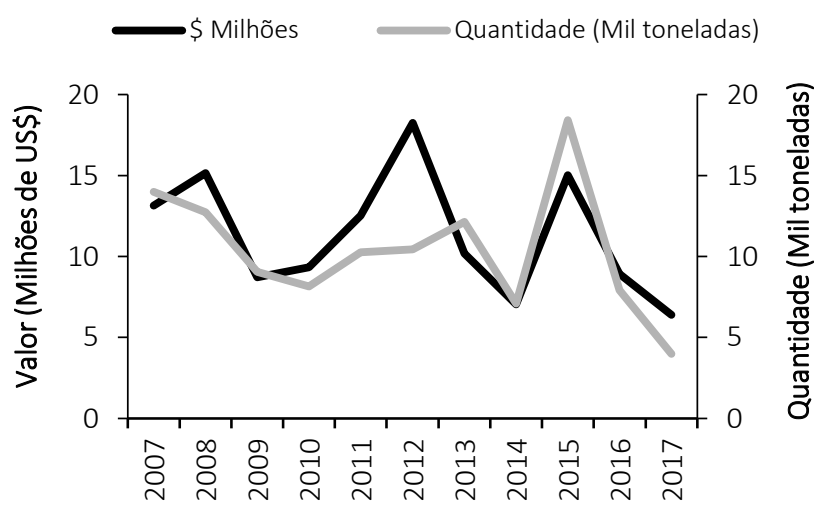

Ano

Figura 1. Evolução da quantidade (Mil toneladas) e do valor (Milhões de US\$ุ) das exportações brasileiras de Castanha-do-pará.

As exportações registraram uma retração a partir de 2015 , caindo de 18,4 mil toneladas para 4,0 mil toneladas em 2017. Tais resultados são explicados em grande parte pela baixa produtividade do segmento, em virtude da escassez de oferta com o envelhecimento dos cajuzeiros (FIEC, 2018).

Na Tabela 3, estão demonstrados ao longo do período avaliado países que foram, em algum momento, mercados importantes para o produto brasileiro. 
Tabela 3. Participação percentual dos principais mercados de destino das exportações brasileiras de Castanha-do-Pará.

\begin{tabular}{ccccccc}
\hline \multirow{2}{*}{ Ano } & \multicolumn{5}{c}{ Países (\%) } \\
\cline { 2 - 7 } & Bolívia & $\begin{array}{c}\text { Estados } \\
\text { Unidos }\end{array}$ & China & Perú & Tunísia & Outros \\
\hline 2007 & 26,2 & 26,6 & 32,7 & 0,0 & 0,2 & 14,2 \\
\hline 2008 & 28,6 & 28,6 & 34,3 & 0,1 & 0,6 & 7,7 \\
\hline 2009 & 6,1 & 18,6 & 27,0 & 3,1 & 3,6 & 41,6 \\
\hline 2010 & 24,0 & 42,5 & 23,0 & 4,4 & 2,2 & 3,8 \\
\hline 2011 & 36,9 & 26,4 & 24,9 & 8,0 & 1,3 & 2,6 \\
2012 & 11,3 & 11,9 & 51,9 & 5,0 & 5,4 & 14,5 \\
\hline 2013 & 40,2 & 23,2 & 14,7 & 16,8 & 3,1 & 1,9 \\
\hline 2014 & 23,9 & 34,5 & 18,9 & 16,2 & 3,8 & 2,7 \\
2015 & 42,5 & 17,1 & 4,9 & 30,1 & 4,9 & 0,5 \\
\hline 2016 & 23,3 & 23,6 & 3,3 & 30,6 & 9,0 & 10,3 \\
\hline 2017 & 15,5 & 17,0 & 1,7 & 55,0 & 10,9 & 0,0 \\
\hline Média & 25,3 & 24,5 & 21,6 & 15,4 & 4,1 & 9,1 \\
\hline
\end{tabular}

Verifica-se que no início da série avaliada, as exportações eram menos diversificadas, de modo que países como China, Estados Unidos e Bolívia detinham boa parte das exportações. Entretanto, a partir de 2009 estes países apresentaram declínio quanto as exportações, evidenciando um aumento na participação de países como Perú, Tunísia e outros. Tais fatores podem ser reflexo da crise econômica de 2008, que causou redução nos investimentos do setor e, consequentemente, impactos nas exportações e outros países acabaram expandindo sua participação.

Os Estados Unidos foram os principais importadores do Brasil nos anos de 2010 e 2014, tendo sido ultrapassado pela Bolívia nos anos seguintes (2011 e 2015). Sua menor participação nas importações do produto ocorreu em 2012, quando importou apenas $11,85 \%$ do total das exportações do produto.

Ademais, verifica-se um crescimento constante na participação por parte do Perú, apresentando-se no ano de 2017 com mais da metade das exportações brasileiras e em contrapartida reduzindo significativamente a participação dos demais players como Bolívia, Estados Unidos e China.

Os resultados do índice Herfindahl-Hirshman (Tabela 4), que considera a participação de todos os países para os quais o Brasil exporta, também demonstram que as exportações brasileiras de Castanha-do-Pará apresentam alta concentração em 8 anos dos 11 avaliados, apresentando-se no ano de 2009 um mercado altamente competitivo e nos anos 2014 e 2016 concentração moderada.
Tabela 4. Concentração das exportações brasileiras de Castanha-do-pará de acordo com o Índice IHH e o número de países em cada período.

\begin{tabular}{ccc}
\hline Ano & IHH & Número de países \\
\hline 2007 & 0,256 & 13 \\
2008 & 0,284 & 13 \\
2009 & 0,096 & 11 \\
2010 & 0,295 & 10 \\
2011 & 0,275 & 9 \\
2012 & 0,316 & 10 \\
2013 & 0,264 & 9 \\
2014 & 0,240 & 7 \\
2015 & 0,305 & 7 \\
2016 & 0,222 & 8 \\
\hline 2017 & 0,367 & 6 \\
\hline Média & 0,265 & 9 \\
\hline
\end{tabular}

Em comparação ao período avaliado o ano de 2007 apresentava mais que o dobro de países importadores em relação a 2017. Acredita-se que estes valores de alta concentração podem ser explicados pelos diversos acordos comerciais, contribuindo com a formação de blocos regionais no mercado mundial.

Um dos maiores indicativos dessa alta concentração é que a estratégia utilizada pelo Brasil com enfoque ou especialização de mercado, visa atender os desejos e as necessidades de mercados específicos. De acordo com Cunha Filho \& Carvalho (2005) altos níveis de concentração podem acarretar riscos, uma vez que colocam as empresas em uma posição de total dependência do mercado, corroborando para que os países exportadores fiquem a mercê de flutuações de demanda.

Diante do exposto, as estratégias para amenizar estes índices caracterizam-se na necessidade de mudanças de atuação de mercado internacional. Assim, a tomada de decisões deve ocorrer no sentido de esforços para adaptar o produto aos desejos e necessidades dos consumidores e superar as inúmeras barreiras existentes nos países que importam esse produto.

O alto grau de concentração das exportações brasileiras é comprovado pelo critério CR4 e CR8 demonstrado na Tabela 5.

De acordo com esse critério, as exportações do produto em análise apresentaram um grau de concentração muito alto para todo o período, em relação ao CR4 (superior a 75\%). Neste sentido, esta medida revela que apenas quatro países compreendem quase a totalidade das exportações. Para o ano de 2017, 98,25\% concentram-se no Peru, Estados Unidos, Bolívia e Tunísia, apresentando o maior valor em todo o período. Em 
relação ao grau de contração CR8, os valores corresponderam a um grau muito alto, com exceção apenas no ano de 2009. No período de 2007 a 2017 a concentração dos países variou de 62,64 a 100\%, com média de 96,34\%, caracterizando de maneira geral concentração muito alta.

Tabela 5. Concentração das exportações brasileiras de Castanha-do-Pará de acordo com o critério CR4 e CR8 (\%) e o número de países em cada período.

\begin{tabular}{cccc}
\hline Ano & CR4 (\%) & CR8 (\%) & Número de países \\
\hline 2007 & 95,22 & 99,19 & 13 \\
2008 & 94,98 & 99,08 & 13 \\
2009 & 51,70 & 62,64 & 11 \\
2010 & 93,94 & 100,00 & 10 \\
2011 & 96,13 & 100,00 & 9 \\
\hline 2012 & 86,81 & 99,12 & 10 \\
\hline 2013 & 94,15 & 99,72 & 9 \\
\hline 2014 & 93,49 & 100,00 & 7 \\
\hline 2015 & 94,62 & 100,00 & 7 \\
\hline 2016 & 87,20 & 100,00 & 8 \\
\hline 2017 & 98,25 & 100,00 & 6 \\
\hline Média & 89,68 & 96,34 & 9 \\
\hline
\end{tabular}

Dentre os estudos encontrados na literatura que revelaram valores de alta concentração em relação a exportação de produtos brasileiros destaca-se: Coelho Junior et al. (2013), que avaliaram a concentração das exportações mundiais de produtos florestais no período de 1961 a 2008; Noce et al. (2005), que estudaram a concentração das exportações no mercado internacional de madeira serrada nos anos de 1997 a 1999; e Oliveira et al. (2017), que verificaram concentração das exportações brasileiras de portas de madeira do ano de 2005 a 2015.

Já na avaliação da desigualdade (Tabela 6), obtida por intermédio do índice de Gini (G) ocorreram oscilações no índice, com estágios de aumento e redução na desigualdade.

Para os anos em análise o grau de desigualdade das exportações variou de 0,374 a 0,750, compreendendo uma média de 0,606 e caracterizando, de maneira geral, desigualdade média a forte.

Nos anos 2007 e 2008 o mercado de exportações apresentou desigualdade forte a muito forte e no ano seguinte (2009) foi reclassificado como de desigualdade fraca a média, segundo a classificação de Câmara (1949) apud Silva et al. (1992). Vale ressaltar mais uma vez que tais reflexos relevam o impacto da crise econômica de 2008, que causou redução nos investimentos do setor e, consequentemente, impactos nas exportações.
Tabela 6. Medidas de desigualdade para as exportações de Castanha-do-Pará, de acordo com o coeficiente de Gini (G), e o número de países em cada período.

\begin{tabular}{ccc}
\hline Ano & Coeficiente de Gini (G) & Número de países \\
\hline 2007 & 0,741 & 13 \\
2008 & 0,750 & 13 \\
2009 & 0,374 & 11 \\
2010 & 0,688 & 10 \\
2011 & 0,647 & 9 \\
\hline 2012 & 0,665 & 10 \\
\hline 2013 & 0,636 & 9 \\
\hline 2014 & 0,515 & 7 \\
\hline 2015 & 0,570 & 7 \\
\hline 2016 & 0,556 & 8 \\
\hline 2017 & 0,521 & 6 \\
\hline Média & 0,606 & 9 \\
\hline
\end{tabular}

Outro ponto observado foi que a partir de 2012, o número de países vem reduzindo gradativamente ao longo do período de análise. Deste modo, apenas um número reduzido de competidores concentra frações cada vez maior das exportações internacionais do produto. Conforme a Secretaria da Indústria, Comércio e Mineração de Amapá - SEICOM (2004) a atividade extrativista da Castanha-do-Pará, apresenta baixa produtividade e renda para o trabalhador decorrente da baixa qualidade e remuneração insuficiente do produto pelos compradores. Outro ponto negativo da cadeia produtiva deste produto é o comércio ilegal. Deste modo, parte da comercialização acaba sendo desviada para países vizinhos sem controle fiscal.

Quando comparados os índices de concentração e desigualdade na qual o primeiro é alto e o segundo médio, verifica-se resultados opostos. De acordo com Hoffmann (2006) tais valores explicam-se pelo fato de que o índice de Gini, analisa proporções, no caso de países e exportações, enquanto as medidas de concentração, como o $\mathrm{IHH}$, determinam a proporção de uma variável (exportações de Castanha-do-Pará) controlada por um número absoluto de agentes (países).

\section{CONCLUSÕES}

A evolução das exportações brasileiras de Castanhado-pará registra uma tendência de decréscimo a partir de 2008, atingindo pico do valor monetário em 2012 e da quantidade em 2015, mesmo ano em que ambos registraram retração gradativa até 2017.

No início da série avaliada, as exportações eram menos diversificadas, entretanto a partir de 2009, alguns 
países apresentaram declínio quanto as importações, evidenciando aumento na participação de outros países.

$O$ Índice $(\mathrm{IHH})$ apresenta valores de alta concentração, da mesma forma que em relação ao CR4 e CR8 as exportações do produto em análise correspondem a um grau de concentração muito alto para todo o período.

Já o índice (G) indica que, apesar de apresentarem uma baixa de países importadores do produto florestal não madeireiro ao longo do período, apenas um número reduzido de competidores concentra frações cada vez maiores das exportações internacionais, caracterizandose de maneira geral como de desigualdade média a forte.

Recomenda-se a análise dos índices em conjunto, com o intuito de evitar conclusões precipitadas. Além disto, o Brasil apresenta condições de expandir suas exportações, desenvolvendo estratégias no sentido de permitir e facilitar a expansão da Castanha-do-Pará e consequentemente acrescendo a quantidade de países envolvidos no processo de exportação.

\section{AGRADECIMENTOS}

O presente trabalho foi realizado com o apoio da Coordenação de Aperfeiçoamento de Pessoal de Nível Superior (CAPES) - Código de Financiamento 001.

\section{REFERÊNCIAS}

BAIN, J.S. Industrial organization. New York: John Wiley, 1959.

CÂMARA, L. A concentração da propriedade agrária no Brasil. Boletim Geográfico, v.7, n.77, p.516-528, 1949.

CARDARELLI, H.R.; OLIVEIRA, A.J. Conservação do leite de Castanha-do-Pará. Scientia Agrícola, v.57, n.4, p.617-622, 2000.

COELHO JUNIOR, L.M. et al. Concentração das exportações mundiais de produtos florestais. Ciência Florestal, v.23, n.4, p.691-701, 2013.

COLLARES, D.G. Castanha-do-Brasil: uma alternativa de reflorestamento. Embrapa Florestas, 2006. Disponível em: https://www.embrapa.br/busca-de-noticias/-

/noticia/17988458/castanha-do-brasil-uma-alternativade-reflorestamento

CUNHA FILHO, M.D.; CARVALHO, R.M. Exportações brasileiras de frutas: diversificação ou concentração de produtos e destinos? 43 Congresso Brasileiro de Economia e Sociologia Rural, p.213, 2005.

FEIJÓ, C.A. et al. Concentração industrial e produtividade do trabalho na indústria de transformação nos anos 90: evidências empíricas. Economia, v.4, n.1, p.19-52, 2003.

FIEC - SISTEMA FEDERAÇÃO DAS INDÚSTRIAS DO ESTADO DO
CEARÁ. Exportações de Castanha de caju registram retração em 2017 no Ceará. FIEC online, 2018. Disponível em: https://www1.sfiec.org.br/fiec-noticias/112087/exportacoes-deCastanha-de-caju-registram-retracao-em-2017-no-ceara

FORMIGONI, I. Exportação de Castanha do Pará é recorde em 2018. Disponível em: http://www.farmnews.com.br/mercado/ exportacao-de-Castanha-do-para/.

GAMA, Z.A.G.P.; SOUSA, Í.Z.G.D. Estrutura e conduta do mercado varejista de madeira serrada em Rio Branco-Acre. Revista Floresta, v.40, n.2, p.355-371, 2010.

HEIMANN, J.P.D. et al. Concentração de mercado de molduras (frame) importadas pelos Estados Unidos, período de 2005 a 2009. Cerne, v.21, n.1, p.59-65, 2015.

HOFFMANN, R. Estatística para economistas. 4.ed. São Paulo: Pioneira, 2006.

LARSON, D.W.; SILVA, M.B.A. Análise do internacional e da demanda por Castanha de caju em países selecionados. Revista Administração de empresas, v.16, n.6, p.07-21, 1976.

MACEDO, R.D.; SOARES, N.S. O desempenho das exportações brasileiras de amêndoas de Castanha-de-caju entre os anos de 2007 e 2011. Informe Gepec, v.19, n.1, p.148-162, 2015.

NOCE, R. et al. Concentração das exportações no mercado internacional de madeira serrada. Revista Árvore, v.29, n.3, p.431-437, 2005.

OLIVEIRA, G.S. et al. Análise dos índices de concentração e desigualdade das exportações brasileiras de Erva-mate (Ilex paraguariensis St. Hill). Revista Espacios, v.38, n.44, p.18, 2017.

OLIVEIRA, G.S. et al. Concentração das exportações brasileiras de portas de madeira. Scientia Agraria Paranaense, v.16, n.4, p.490-494, 2017.

RESENDE, M. Medidas de Concentração Industrial: uma resenha. Revista Análise Econômica, v.12, n.21/22, p.24-33, 1994.

SCHMIDT, C.A.J.; LIMA, M.A. Índices de concentração. Série de documentos de trabalho, v.8, n.13, p.8, 2002.

SEICOM - SECRETARIA DE INDÚSTRIA, COMÉRCIO E MINERAÇÃO DO AMAPÁ. Da Amazônia para o mundo. Projeto Castanha, p.79-82, 2004

SILVA, J.C.G.L. et al. Estrutura de mercado do setor de papel e celulose no Brasil. Encontro brasileiro de economia e planejamento florestal, p.485-499, 1992.

SOARES, P.R.C. et al. Concentração e desigualdade nas importações norte-americanas de celulose. Scientia Forestalis, v.42, n.102, p.173-179, 2014.

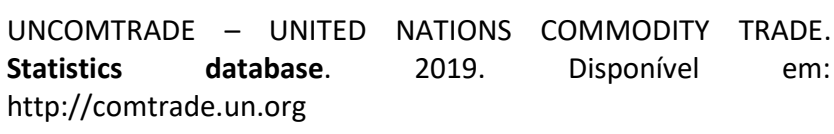

Recebido em 02-05-2019 Aceito em 28-06-2019 